\title{
MicroRNA-125b-2 confers human glioblastoma stem cells resistance to temozolomide through the mitochondrial pathway of apoptosis
}

\author{
LEI SHI $^{1 *}$, SHUGUANG ZHANG $^{1 *}$, KUN FENG $^{2 *}$, FURONG WU $^{2 *}$, YI WAN $^{3}$, ZHIMIN WANG $^{3}$, \\ JUNXIA ZHANG ${ }^{4}$, YINYI WANG ${ }^{4}$, WEI YAN ${ }^{4}$, ZHEN FU $^{4}$ and YONGPING YOU ${ }^{4}$ \\ Departments of ${ }^{1}$ Neurosurgery and ${ }^{2}$ Gastroenterology, The First People's Hospital of Kunshan affiliated with \\ Jiangsu University, Suzhou 215300; ${ }^{3}$ Department of Neurosurgery, Suzhou Kowloon Hospital affiliated with \\ Shanghai Jiao Tong University School of Medicine, Shanghai 200000; ${ }^{4}$ Department of Neurosurgery, \\ The First Affiliated Hospital of Nanjing Medical University, Nanjing 210029, P.R. China
}

Received June 22, 2011; Accepted August 10, 2011

DOI: $10.3892 /$ ijo.2011.1179

\begin{abstract}
MicroRNAs (miRNAs) are small, non-coding RNA molecules that regulate protein expression by cleaving or repressing the translation of target mRNAs. miR-125b, one of the neuronal miRNAs, was recently found to be necessary for stem cell fission and for making stem cells insensitive to chemotherapy signals. Temozolomide (TMZ) is a promising chemotherapeutic agent for treating glioblastomas. However, resistance develops quickly and with a high frequency. Given the insensitivity of some glioblastomas to TMZ and the hypothesis that glioma stem cells cause resistance to drug therapy, exploring the functions and mechanisms of miR-125b action on TMZ-treated glioblastoma stem cells would be valuable. In this study, we found that miR-125b-2 is overexpressed in glioblastoma multiforme tissues and the corresponding stem cells (GBMSC); downregulation of miR-125b-2 expression in GBMSC could allow TMZ to induce GBMSC apoptosis. Additionally, the expression of the anti-apoptotic protein Bcl-2 was decreased after the TMZ+miR-125b-2 inhibitor treatment, while the expression of the proapoptotic protein Bax was increased. Further research demonstrated that the induction of apoptosis in GBMSC is also associated with increased cytochrome $\mathrm{c}$ release from mitochondria, induction of Apaf-1, activation of caspase-3 and poly-ADP-ribose polymerase
\end{abstract}

Correspondence to: Dr Lei Shi, Department of Neurosurgery, The First People's Hospital of Kunshan affiliated with Jiangsu University, Suzhou 15300, P.R. China

E-mail: shileigff@126.com

Dr Yongping You, Department of Neurosurgery, The First Affiliated Hospital of Nanjing Medical University, Nanjing 210029, P.R. China E-mail: yyp19@njmu.edu.cn

${ }^{*}$ Contributed equally

Key words: microRNA, temozolomide, peptide nucleic acids, apoptosis, Bax, Bcl-2
(PARP). Taken together, these results suggest that miR-125b-2 overexpression might confer glioblastoma stem cells resistance to TMZ.

\section{Introduction}

Malignant gliomas, the most common primary malignant tumors of the brain, are aggressive, highly invasive, and neurologically destructive. Despite the combination of surgery, chemotherapy, and radiotherapy, the median survival duration of patients with glioblastoma multiforme (GBM), the most aggressive type of malignant glioma, is only 9-12 months (1). Currently, firstline therapy for all GBM patients post-surgery consists of the combination of temozolomide (TMZ) and regional fractionated radiation, followed by TMZ alone (2).

TMZ, a 3-methyl derivative of mitozolomide, is an alkylating chemotherapeutic drug that readily crosses the blood-brain barrier in glioblastoma patients. It has demonstrated anti-tumor activity and a relatively low toxicity in phase II and III clinical trials in patients with malignant glioblastomas. It can efficiently inhibit the proliferation of glioma cells and induce apoptosis. However, the action of TMZ on glioblastoma cells remains largely undefined, and glioblastomas are relatively resistant to the cytotoxic effects of TMZ (3). Recent findings support the existence of a stem cell-derived origin of gliomas (4). Gliomaderived stem cells (GSCs) have been isolated from both human brain tumors and several glioma cell lines. GSCs are crucial for glioma malignancy and may be the consequence of a transformation of the normal neural stem cell compartment (5). These findings are compatible with the observation that gliomagenesis is frequently associated with the presence of adult brain stem cells, suggesting that there is a cellular and genetic mechanism that controls adult neurogenesis that might contribute to brain tumorigenesis and thereby allow the identification of new therapeutic strategies. However, until now there have been no valid results on TMZ and stem cells. In considering glioblastoma cell $\mathrm{TMZ}$ resistance, we believe that seeking a break from GSCs may become a new direction for the TMZ treatment resistance of glioblastoma cells. 
MicroRNAs (miRNAs) are small non-coding RNAs whose function as modulators of gene expression is crucial for the proper control of cell growth. According to recent reports, stem cell division is regulated by the miRNA pathway (6). miR-125b, one of the neuronal miRNAs, has been found necessary for stem cell fission to bypass the normal G1/S checkpoint and make stem cells insensitive to the chemotherapy signals that would normally stop the cell cycle at the G1/S transition (7). Global microRNA expression analysis in human malignant glioma cells by Winkler et al revealed two novel examples of miRNA-mediated therapy resistance, which might provide new targets for the treatment of this tumor (8). One of these examples involved miR-125b-2. In this study, we found that miR-125b-2 was overexpressed in glioblastoma tissues, in tissues from postoperative recurrence of glioblastoma multiforme after TMZ treatment (PRGMTTT) and in stem cells compared to normal brain tissue $(\mathrm{P}<0.05)$. Thus, we infer that miR-125b-2 somehow favors tumor growth by impeding apoptosis and confers TMZ resistance on glioblastoma stem cells.

To prove this hypothesis, we used peptide nucleic acid (PNA)-mediated miRNA inhibition to inhibit miR-125b-2 expression in glioblastoma stem cells and observed its effect on the sensitivity of glioblastoma stem cells to TMZ. Peptideconjugated PNAs are the most effective at achieving miRNA inhibition. PNAs are artificial oligonucleotides constructed on a peptide-like backbone. PNAs have a stronger affinity for and greater specificity to DNA or RNA than do natural nucleic acids, and they are resistant to nucleases, which is an essential characteristic for a miRNA inhibitor that will be exposed to serum and cellular nucleases. To increase cell penetration, PNAs were conjugated with cell penetrating peptides (CPPs) at the N-terminal. Additionally, Tat-modified-conjugated PNA showed the most effective cell penetration in the absence of transfection reagents and most effectively inhibited miRNAs (9). Here, we used PNAs ${ }^{\mathrm{TM}}$ miRNA inhibitor produced by Panagene (Daejeon, Korea).

We found that the PNA miR-125b-2 inhibitor effectively inhibited miR-125b-2 expression in glioblastoma stem cells in the absence of a transfection reagent; additionally, compared to control cells, neither TMZ nor miR-125b-2 downregulation alone caused apoptosis in glioblastoma stem cells. However, when the expression of miR-125b-2 was downregulated by the PNA miR-125b-2 inhibitor in glioblastoma stem cells before TMZ treatment, TMZ could then induce significant apoptosis. Next, we sought to investigate the mechanism of miR-125b-2 downregulation on TMZ-induced glioblastoma stem cell apoptosis. Pro-apoptotic Bax and anti-apoptotic Bcl-2 proteins are known to regulate the apoptosis of glioma cells (10). Bcl-2, which resists induction of apoptosis, constitutes one major obstacle to radiotherapy and chemotherapy in many cancer cells (11). Bax plays a major role in the apoptotic response of glioblastoma multiforme cells, the high expression of which is shown to correlate with an increased survival of GBM patients (12). Also, a low Bax:Bcl-2 ratio is usually observed in glioblastoma multiforme patients (13).

Therefore, we investigated the levels of these apoptosis regulatory proteins following treatment of glioblastoma stem cells with the PNA miR-125b-2 inhibitor and TMZ, alone or combination. We found that pretreating glioblastoma stem cells with the PNA miR-125b-2 inhibitor decreased the level of Bcl-2 protein and increased the level of Bax protein, compared to treatment with TMZ alone. A shift in the ratio of Bax/Bcl-2 could stimulate the release of cytochrome $\mathrm{c}$ from mitochondria into cytosol. In the cytosol, cytochrome $\mathrm{c}$ associates with Apaf-1. In the presence of dATP/ATP, Apaf-1 then binds to and activates caspase-9. Activation of initiator caspases- 8 or -9 causes proteolytic activation of a common set of downstream proteases, including caspase-3 and -7, which results in cell death induction. However, the apoptosisinitiating pathways that are induced by a combination of the PNA miR-125b-2 inhibitor and TMZ therapy in GBMSC are poorly understood.

Caspases are cysteine proteinases that have been shown to be specifically involved in the initiation and execution phases of apoptosis. The caspases, especially caspase-3, are known to act downstream of $\mathrm{Bax} / \mathrm{Bcl}-2$ and play a key role in the execution of apoptosis (14). Previous research by us showed that TMZ could increase the activity of caspase-3 (15). Herein, we demonstrated that pretreatment with the PNA miR-125b-2 inhibitor increases TMZ-induced release of cytochrome $\mathrm{c}$ and the activation of caspase-3.

Taken together, this study demonstrates that the overexpression of miR-125b-2 in glioblastoma stem cells does not function as an anti-apoptosis factor, but instead protects cells from TMZ-induced apoptosis. In addition, we provide evidence that the PNA miR-125b-2 inhibitor regulates TMZ-induced apoptosis, in part by increasing the release of cytochrome $\mathrm{c}$ from mitochondria in a caspase-independent manner.

\section{Materials and methods}

Primary glioblastoma cell cultures and treatments. Human glioblastoma tissues and PRGMTTT samples were obtained from the first affiliated hospital of Nanjing Medical University and Suzhou Kowloon Hospital affiliated with Shanghai Jiao Tong University School of Medicine after informed consent was obtained from adult patients diagnosed with WHO-IV glioma. Primary glioblastoma cell cultures were obtained after mechanical dissociation, according to the technique described by Darling (16). The cells were subcultured in $2 \%$ FCS for 1 week before in vitro analyses to prevent the growth of contaminating rodent fibroblasts, after which the cells were cultured in $10 \%$ FCS and antibiotics. Glial origin was confirmed by morphology and by staining with antiGFAP MoAb clone 6F2 (Dako, Glostrup, Denmark). All of the experiments on these cells were done before passage 5 . Normal human brain tissues were obtained after informed consent from the patients with severe traumatic brain injury (TBI) who needed post-trauma surgery. The grey matter was dissected after being removed and dispersed repeatedly after washing in phosphate buffered sodium (PBS). Then primary astrocytes were also cultured according to the technique described by Darling (16). Primary glioblastoma cells with high levels of mature miR-125b-2 were identified by TaqManbased real-time quantification RT-PCR.

Experiments were divided into five groups: control group, PNA miRNAnc group, PNA miR-125b-2 inhibitor group, TMZ group, and PNA miR-125b-2 inhibitor+TMZ group. Cells were treated with the PNA miR-125b-2 inhibitor complexed to $600 \mu \mathrm{M} \mathrm{TMZ}$ for $72 \mathrm{~h}$ at $37^{\circ} \mathrm{C}$ with $5 \% \mathrm{CO}_{2}$. 
Magnetic cell separation of CD133-positive cells. Cells were dissociated and resuspended in PBS containing $0.5 \%$ bovine serum albumin and $2 \mathrm{mmol} / \mathrm{l}$ EDTA. For magnetic labeling, CD133/1 Micro Beads were used (Miltenyi Biotech). Positive magnetic cell separation (MACS) was done using several MACS columns in series. Cells were stained with CD133/2-PE (Miltenyi Biotech) and analyzed on a BD FACSCalibur.

Oligonucleotide transfection. The PNA miR-125b-2 inhibitor and the negative control were chemically synthesized by Panagene. One day before transfection, $1.5 \times 10^{5}$ cells were seeded per well in $1.5 \mathrm{ml}$ of the appropriate complete growth medium without antibiotics. Cells were incubated in stem cellpermissive DMEMF12 medium supplemented with $20 \mathrm{ng} / \mathrm{ml}$ of each human recombinant epidermal growth factor, human recombinant basic fibroblast growth factor (both from R\&D Systems), and human leukemia inhibitory factor (Chemicon), and 2\% B27 (Life Technologies). Then, CD133-positive primary glioma cells were co-cultured with the PNA miRNA inhibitors at a final PNA miRNA inhibitor concentration of $2 \mu \mathrm{M}$ according to the manufacturer's instructions and, at the time, the cells were 70-90\% confluent. The transfected CD133-positive glioma cells with decreased levels of mature miR-125b-2 were identified by TaqMan-based real-time quantification RT-PCR.

Real-time quantification of miRNAs by stem-loop RT-PCR. For the TaqMan-based real-time reverse transcription-polymerase chain reaction (RT-PCR) assays, the ABI 7300 HT Sequence Detection system (Applied Biosystems, Foster City, CA) was used. RNA was extracted from primary glioma cells using miRNA Isolation kit (Invitrogen, Carlsbad, USA) according to the manufacturer's instructions. All the primers and probes of the miR-125b-2 and RNU6B endogenous controls for the TaqMan miRNA assays were purchased from Applied Biosystems. Real-time PCR was performed as described in Chen et al (17). Relative gene expression was calculated via a $2^{-\Delta \Delta C t}$ method (18).

Cell viability assay. The effect of PNA miR-125b-2 inhibitor and TMZ on the cellular proliferation and viability of human glioblastoma multiforme stem cells was determined by the 3-[4,5-dimethylthiazol-2-yl]-2,5 diphenyltetrazolium bromide (MTT) assay according to the manufacturer's instructions. Briefly, $1 \times 10^{4}$ cells were plated in 96-well culture plates and treated with the PNA miR-125b-2 inhibitor and/or TMZ for 1, 2, 4 and 6 days. The cell proliferation assay was performed as described (19). The absorbance was measured at $540 \mathrm{~nm}$ using an enzyme-linked immunosorbent assay plate reader. All data points represent the means of a minimum of 6-wells. The viability of untreated cells was assumed to be $100 \%$.

Hoechst 33258 staining for morphological analysis of apoptosis. CD133-positive primary glioblastoma cells were seeded on sterile cover glasses placed in the 6-well plates; the cells were incubated with the PNA miR-125b-2 inhibitor and/or TMZ for 6 days. After each treatment, the cells were washed with phosphate-buffered saline (PBS) and fixed with $4 \%$ paraformaldehyde for $10 \mathrm{~min}$ before incubation with $50 \mu \mathrm{M}$ Hoechst 33258 staining solution for $10 \mathrm{~min}$. Apoptotic morphological changes in the nuclear chromatin of cells were detected, and then counted under a light microscope. The percentage of apoptotic cells was calculated from three separate experiments.

Quantitative analysis of apoptotic cells by flow cytometry. CD133-positive primary glioblastoma cells were plated in 12-well plates and treated with the PNA miR-125b-2 inhibitor and/or TMZ for 6 days. The apoptosis ratio was analyzed using an Annexin V FITC Apoptosis Detection Kit (BD Biosciences, San Diego, CA) according to the manufacturer's instructions. Briefly, cells were harvested after the treatment, washed with cold PBS, and subjected to Annexin V/FITC and propidium iodide staining in binding buffer at room temperature for $15 \mathrm{~min}$ in the dark. Apoptotic cells, stained with Annexin V/FITC and propidium iodide, were analyzed by fluorescence activated cell sorting (FACSCalibur, BD Biosciences, San Jose, CA) using CellQuest 3.3 software. Annexin V/FITC and propidium iodide double stain was used to evaluate the percentages of apoptosis. Annexin $\mathrm{V}^{-}$and $\mathrm{PI}^{-}$cells were used as controls. Annexin $\mathrm{V}^{+}$and $\mathrm{PI}^{-}$cells were designated as apoptotic and Annexin $\mathrm{V}^{+}$and $\mathrm{PI}^{+}$ cells displayed necrotic features. Tests were repeated in triplicate.

Western blot analysis. To determine the levels of protein expression, soluble proteins were isolated by lysis buffer $(137 \mathrm{mM}$ $\mathrm{NaCl}, 15 \mathrm{mM}$ EGTA, $0.1 \mathrm{mM}$ sodium orthovanadate, $15 \mathrm{mM}$ $\mathrm{MgCl}_{2}, 0.1 \%$ Triton X-100, $25 \mathrm{mM}$ MOPS, $100 \mu \mathrm{M}$ phenylmethylsulfonyl fluoride and $20 \mu \mathrm{M}$ leupeptin, adjusted to $\mathrm{pH}$ 7.2). One-dimensional sodium dodecyl sulfate (SDS)-polyacrylamide gel electrophoresis was performed with a corresponding gel concentration using the discontinuous buffer system of Laemmli (Bio-Rad Laboratories, Richmond, CA). The electrophoresed proteins were transferred to a polyvinylidene difluoride membrane and subjected to immunoblot analysis with antibodies to Bax, Bcl-2, cytochrome c, Apaf-1 and PARP (used at a 1/200 dilution, Santa Cruz Biotechnology). The reaction was detected with enhanced chemiluminescence (Amersham Life Science, Arlington Heights, IL). The membranes were reblotted with a $\beta$-actin antibody (1/2000, Santa Cruz Biotechnology) after washing to check for equal loading of the gel.

Caspase-3 activity assay. The activity of caspase-3 was determined using the Caspase-3 activity kit (Beyotime Institute of Biotechnology, Haimen, China). To evaluate the activity of caspase-3, cells were homogenized in $100 \mathrm{ml}$ reaction buffer (1\% NP-40, 20 mM Tris- $\mathrm{HCl}$ (pH 7.5), $137 \mathrm{mM}$ Nad and 10\% glycerol) containing $10 \mathrm{ml}$ caspase-3 substrate (Ac-DEVD-pNA) $(2 \mathrm{mM})$ after all treatments. Lysates were incubated at $37^{\circ} \mathrm{C}$ for $2 \mathrm{~h}$. Samples were measured with an ELISA reader at an absorbance of $405 \mathrm{~nm}$.

Statistical analysis. All tests were done using SPSS Graduate Pack 11.0 statistical software (SPSS, Chicago, IL). Descriptive statistics including mean and SE along with one-way ANOVAs were used to determine significant differences. $\mathrm{P}<0.05$ was considered significant.

\section{Results}

Evaluation of miR-125b-2 expression in human glioblastoma multiforme and normal brain tissues. In our previous research, 
A

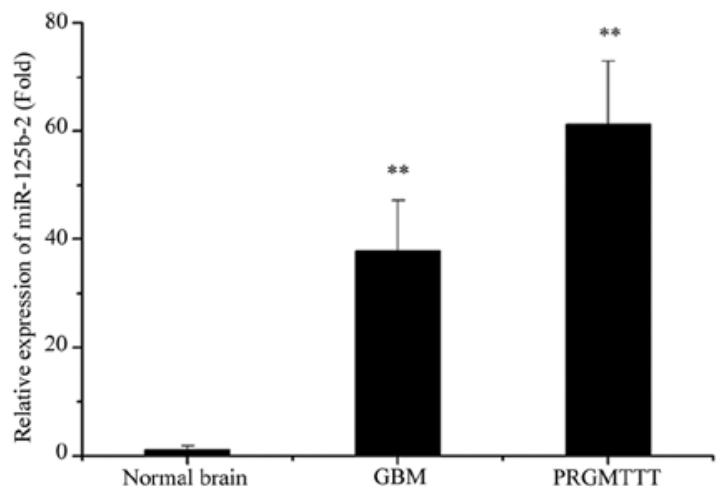

B

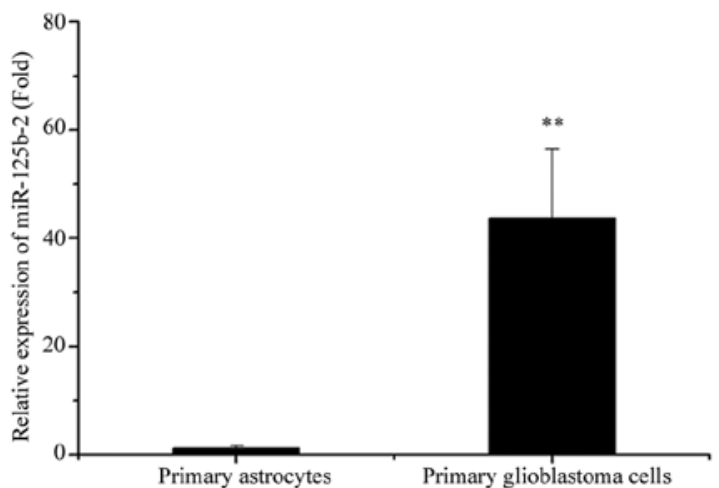

$\mathrm{C}$

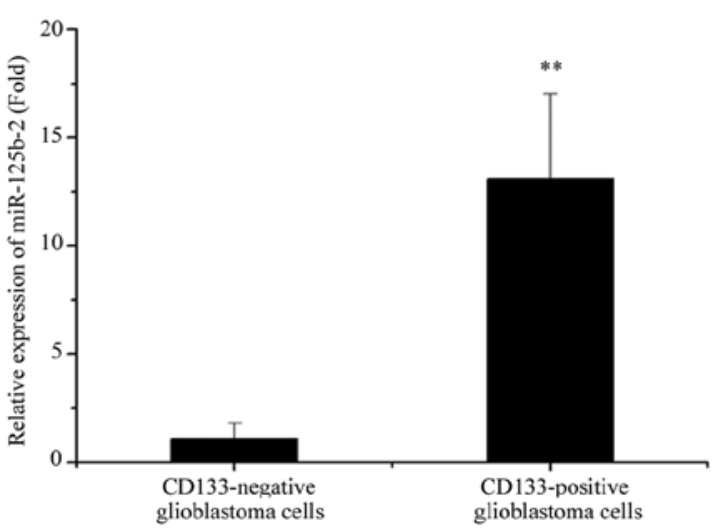

Figure 1. miR-125b-2 expression in human glioblastoma multiforme tissues and normal brain tissues. (A) TaqMan-based real-time stem-loop RT-PCRs for miR-125b-2 were performed with primers specific for mature miRNAs on human normal brain tissues, glioblastoma multiforme tissues and postoperative recurrence of glioblastoma multiforme tissues after TMZ treatment. The column represents the relative expression of miR-125b-2 in the above tissues. ${ }^{* *} \mathrm{P}<0.01$, compared to normal brain tissues. (B) Primary cultured glioblastoma cells with high levels of mature miR-125b-2 were identified by TaqMan-based real-time quantification RT-PCR. The column represents the relative expression of miR-125b-2 in above tissues. ${ }^{* *} \mathrm{P}<0.01$, compared with normal brain tissues. (C) CD133-positive and CD133-negative glioblastoma multiforme cells were first separated by MACS. Next, real-time RT-PCR was used to analyze the expression of miR-125b-2 in CD133-positive and CD133negative glioblastoma multiforme cells. The column represents the relative expression of miR-125b-2 in CD133-positive or CD133-negative U251 cells. ${ }^{* *} \mathrm{P}<0.01$, compared to the CD133-negative group.

we showed that miR-125b had a markedly low expression in human glioblastoma U251 cells, especially in CD133-positive U251 cells (20). However, in this study, we detected the miR$125 \mathrm{~b}-2$ expression levels in human glioblastoma multiforme tissues (WHO-IV glioma tissues) and found that miR-125b-2 was overexpressed in most glioblastoma multiforme tissues and in all postoperative recurrences of glioblastoma multiforme tissues after TMZ treatment (PRGMTTT) compared to normal brain tissue $(\mathrm{P}<0.05)$ (Fig. 1A). Considering the actual function of miR-125b-2 in human glioblastoma multiforme tissue may be different from its function in U251 cells, and because we are studying its function in a clinical setting, we cultured primary human glioblastoma cells from adult patients who were diagnosed with WHO-IV glioma with miR-125b-2 overexpression (Fig. 1B) and separated the CD133-positive cells by magnetic cell separation. We found that miR-125b-2 was more strongly expressed in CD133-positive glioblastoma cells than in CD133negative glioblastoma cells $(\mathrm{P}<0.01)$ (Fig. 1C). We presume that the markedly elevated miR-125b-2 in CD133-positive cells might be a critical factor that contributed to the malignant appearance in human glioblastoma.

Evaluation of viability and apoptotic death morphologically in glioblastoma multiforme stem cells. Previous research has shown that all CD133-positive glioblastoma cells tested are resistant to temozolomide-induced cell death at the maximum concentrations reached in the spinal fluid and in the plasma (21). In this study, CD133-positive glioblastoma cells were treated for 2, 4 and 6 days with increasing doses of TMZ. As shown in Fig. 2A, 6 days of culture in the presence of $<600 \mu \mathrm{M}$ TMZ did not lead to any reduction in the number of CD133-positive glioblastoma cells (glioblastoma multiforme stem cells, GBMSC). Cultured at higher concentrations, treatment with $600 \mu \mathrm{M} \mathrm{TMZ}$ for 6 days induced significant proliferation inhibition. The PNA $^{\mathrm{TM}}$ miRNA inhibitor was reported to effectively knockdown miRNA expression (22). The regulation of miR-125b-2 by the inhibitor was verified by TaqMan-based real-time RT-PCR, as shown in Fig. 2B. We have previously shown that miR-125b can inhibit the proliferation of CD133-positive U251 cells (20). In this study, we also aimed to explore whether downregulating miR-125b-2 could affect the proliferation of CD133-positive glioblastoma cells derived from clinic tissues. Next, the lowest level of miR-125b-2 expression was achieved by treatment with the miR-125b-2 inhibitor in CD133-positive glioblastoma cells (Fig. 2B). Interestingly, we found that the PNA miR-125b-2 inhibitor alone also decreased the cell viability of CD133positive glioblastoma cells (Fig. 2C). As shown in Fig. 2C, treatment of CD133-positive glioblastoma cells with the PNA miR-125b-2 inhibitor for 2 days did not result in a significant reduction in cell viability, whereas treatment with the PNA miR-125b-2 inhibitor for 4 and 6 days resulted in a statistically different reduction in cell viability $(\mathrm{P}<0.01)$. As a result, it seemed that both the $600 \mu \mathrm{M} \mathrm{TMZ}$ and the PNA miR-125b-2 inhibitor could inhibit the viability of CD133-positive glioblastoma cells. Meanwhile, a preliminary screen was conducted to assess the combined effect of the PNA miR-125b-2 inhibitor and TMZ on the cellular viability of CD133-positive glioblastoma cells at different time-points. In CD133-positive glioblastoma cells, the combination treatment with $600 \mu \mathrm{M}$ TMZ and the PNA miR-125b-2 inhibitor reduced cell viability to $23.9 \%$ (Fig. 2C). Analysis with SPSS software demonstrated statistically significant differences between any of the single treatments and the combination treatment, as indicated on Fig. $2 \mathrm{C}(\mathrm{P}<0.01)$.

At present, there are many reports that treatment with TMZ alone does not induce any apoptosis but induces autophagy in 

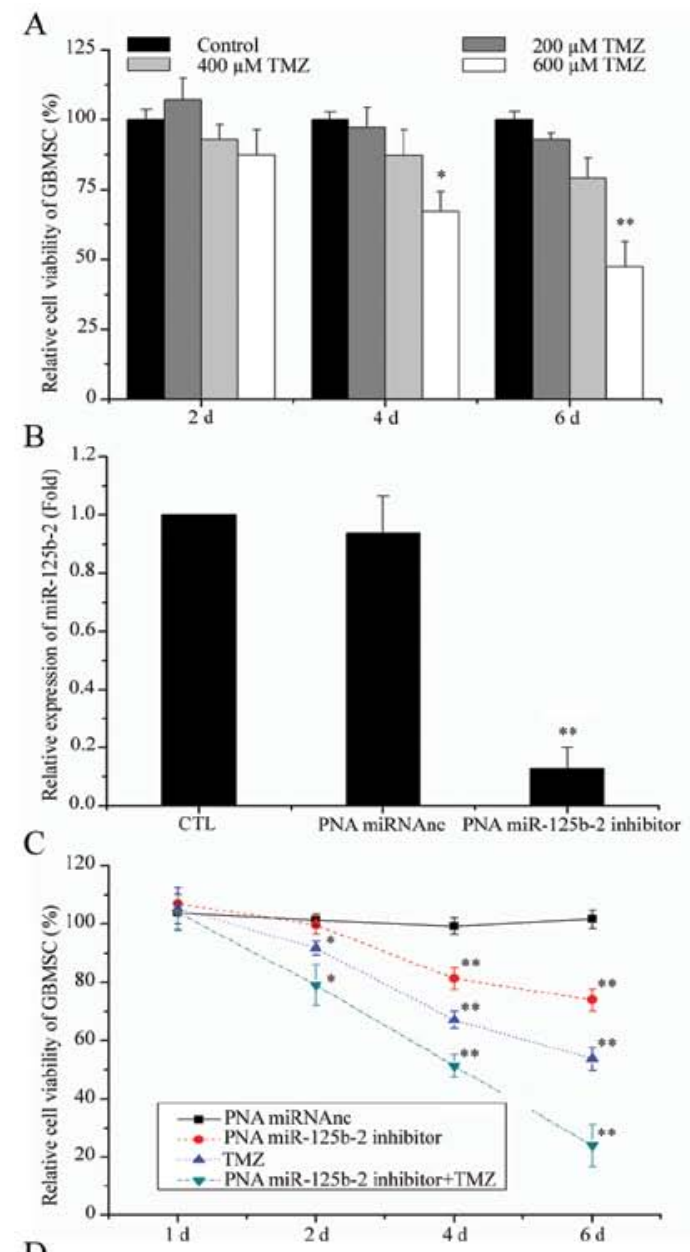

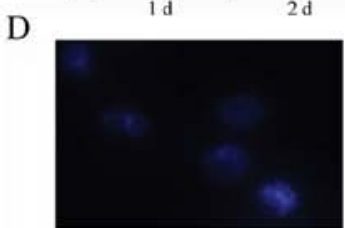

E

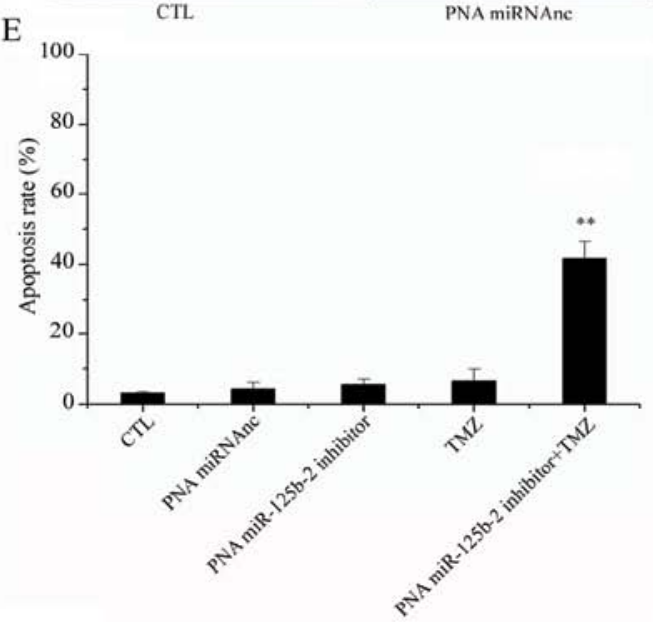

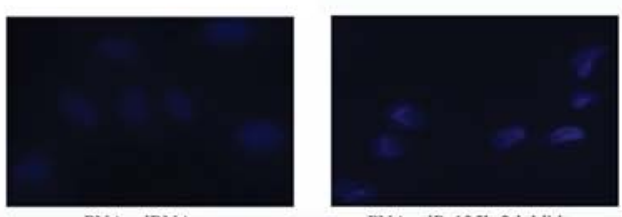

PNA miR-125h-2 inhihitor

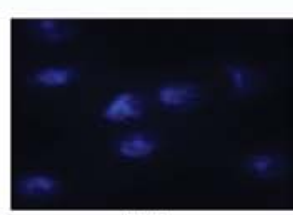

TMZ

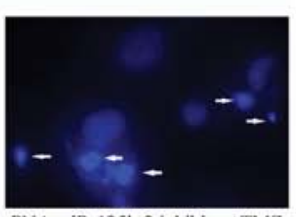

PNA miR-125b-2 inhibitor+TMZ

Figure 2. TMZ and the PNA miR-125b-2 inhibitor inhibit the proliferation and cell viability of CD133-positive glioblastoma cells (GBMSC) and create morphological features of apoptosis. (A) The effects of TMZ on CD133-positive glioblastoma cells were measured using the MTT assay. Cells treated with TMZ from 0 to $600 \mu \mathrm{M}$ for 6 days were subjected to the MTT cell proliferation assay. The viability of untreated cells was considered as $100 \%$. ${ }^{*} \mathrm{P}<0.05$ and ${ }^{* *} \mathrm{P}<0.01$, compared with the control group. (B) Levels of miR-125b-2 expression in CD133-positive glioblastoma cells after transfection with the PNA miR-125b-2 inhibitor and PNA miRNAnc. A significant difference between the PNA miR-125b-2 inhibitor and CTL or PNA miRNAnc was indicated by ${ }^{* *} \mathrm{P}<0.01$. CTL indicates control. PNA miRNAnc indicates PNA miRNA negative control. (C) The effects of treatment with $600 \mu \mathrm{M} \mathrm{TMZ}$ and the PNA miR-125b-2 inhibitor, alone or in combination, on CD133-positive glioblastoma cells were measured using the MTT assay. Cells treated with the PNA miR-125b-2 inhibitor complexed to $600 \mu \mathrm{M}$ TMZ for 6 days were subjected to the MTT cell proliferation assay. The viability of untreated cells was considered $100 \%$. ${ }^{*} \mathrm{P}<0.05$, compared with the PNA miRNAnc group. (D) The Hoechst 33258 staining assay was used to assess cell apoptosis in GBMSC. Photomicrographs show that the combination of the PNA miR-125b-2 inhibitor and TMZ treatment mediated an increase in GBMSC apoptosis. Arrows indicate apoptotic cells. (E) Bar graphs represent the percentage of apoptotic cells counted from each group. Data are presented as the means of triplicate experiments. Significant differences are indicated by ${ }^{*} \mathrm{P}<0.05$ and ${ }^{* * *} \mathrm{P}<0.01$. 


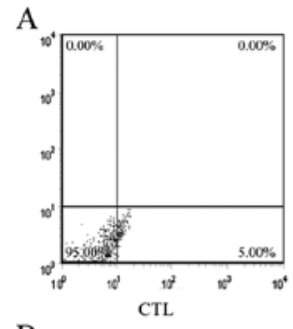

B
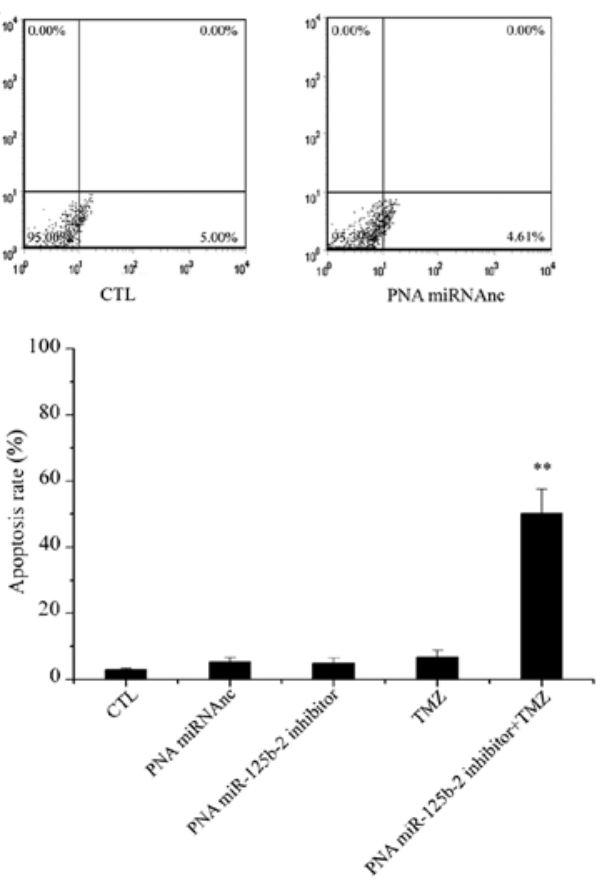
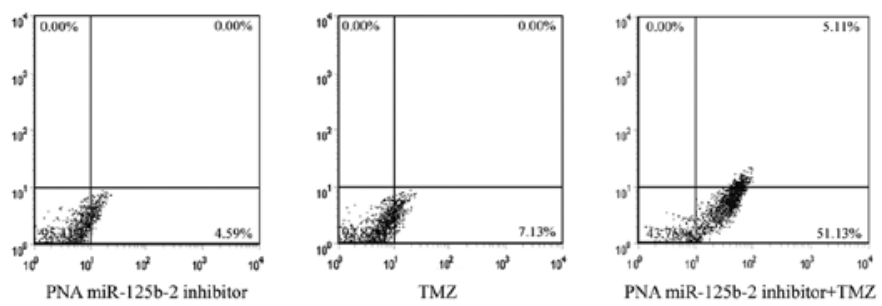

Figure 3. Combination of the PNA miR-125b-2 inhibitor and TMZ therapy resulted in a significantly higher number of apoptotic cells in GBMSC, as analyzed by flow cytometry. GBMSC were treated with the PNA miR-125b-2 inhibitor and/or TMZ for 6 days. After all treatments, cells were harvested and double stained for Annexin $\mathrm{V}$ and propidium iodide and analyzed by flow cytometry. Early apoptotic cells are Annexin $\mathrm{V}^{+} / \mathrm{PI}^{-}$, late apoptotic cells are Annexin $\mathrm{V}^{+} / \mathrm{PI}^{+}$, necrotic cells are Annexin $\mathrm{V}^{-} / \mathrm{PI}^{+}$and healthy cells are Annexin $\mathrm{V}^{-} / \mathrm{PI}^{-}$. (A) A representative experiment of the three performed is shown. Neither the PNA miR-125b-2 inhibitor nor TMZ induced a significantly high number of apoptotic cells in GBMSC. The combination of the PNA miR-125b-2 inhibitor and TMZ treatment induces a significantly higher number of apoptotic cells in GBMSC. (B) Bar graphs represent the percentage of apoptotic cells calculated from each group. Data are presented as the means of triplicate experiments. Significant differences between the TMZ+PNA miR-125b-2 inhibitor and TMZ or the PNA miR-125b-2 inhibitor treated cells are indicated by ${ }^{* *} \mathrm{P}<0.01$.

glioblastoma cells (23). To determine whether the decrease in cell viability after TMZ and PNA miR-125b-2 inhibitor treatment is the result of apoptosis in CD133-positive glioblastoma cells, Hoechst 33258 fluorescence staining was done according to the manufacturer's instructions to detect the apoptotic cells. Morphological features of apoptosis were observed in the TMZ+PNA miR-125b-2 inhibitor treated cells and were counted to determine the amount of apoptotic cell death based on characteristic morphological features. All treatment groups were examined under fluorescence microscopy and cells were counted to determine the percentage of apoptotic cells. There was no significant apoptosis found in cells that received TMZ or the PNA miR-125b-2 inhibitor treatment alone (Fig. 2D). Morphological observation showed that after a pretreatment with the PNA miR-125b-2 inhibitor, TMZ could significantly induce apoptosis in CD133-positive glioblastoma cells compared to the control cells $(\mathrm{P}<0.05)$ (Fig. 2E).

Explicit evaluation of the apoptosis rate by FACS analysis. Fluorophore-labeled Annexin V (a protein that exhibits nanomolar affinity for phosphatidylserine) binding to externalized phosphatidylserine has been extensively employed as a reliable marker of apoptosis (24). FACS analysis was performed to detect apoptotic cells following the combined use of the PNA miR-125b-2 inhibitor and/or TMZ in human primary CD133positive glioblastoma cells (GBMSC) (Fig. 3). Untreated cells served as a negative control. Percentages of apoptotic cells are shown in the histogram. Previous research has shown that down-regulation of miR-125b decreases human glioma cell proliferation and enhances the sensitivity of human glioma cells to ATRA-induced apoptosis (21-26). Das et al recently showed that TMZ could induce U87MG cell apoptosis (26). However, as shown in Fig. 3, neither the PNA miR-125b-2 inhibitor nor TMZ alone induced any significant apoptosis in GBMSC, compared to the control cells $(\mathrm{P}>0.05)$. Compared to the single PNA miR-125b-2 inhibitor or TMZ treatment in GBMSC, the combination of the PNA miR-125b-2 inhibitor and TMZ therapy caused a significantly higher level $(\sim 50 \%)$ of apoptotic death $(\mathrm{P}<0.01)$, suggesting that induction of apoptosis developed in the cells co-treated with the PNA miR-125b-2 inhibitor and TMZ.

Combination of the PNA miR-125b-2 inhibitor and TMZ therapy induced GBMSC apoptosis via an increase in Bax: $B c l-2$ ratio. Previous studies have shown that expression disorders of the Bcl-2 family of proteins in human glioblastoma and cell lines enhance cell survival by inhibiting apoptosis (27). The Bcl-2 family, including Bcl-2, Bcl- $\mathrm{X}_{\mathrm{L}}$, $\mathrm{Bax}$, and $\mathrm{Bad}$, regulates various steps in apoptosis. Bcl-2 and $\mathrm{Bcl}-\mathrm{X}_{\mathrm{L}}$ block cell death, whereas Bax and Bad promote programmed cell death (28). Preclinical studies have shown that the ectopic expression of Bcl-2 confers resistance on several chemotherapeutic agents, including TMZ (26). The increase in the Bax:Bcl-2 ratio is thought to disrupt the resistance of glioma cells to anticancer therapy by modulating the apoptotic cascade (29). 
A

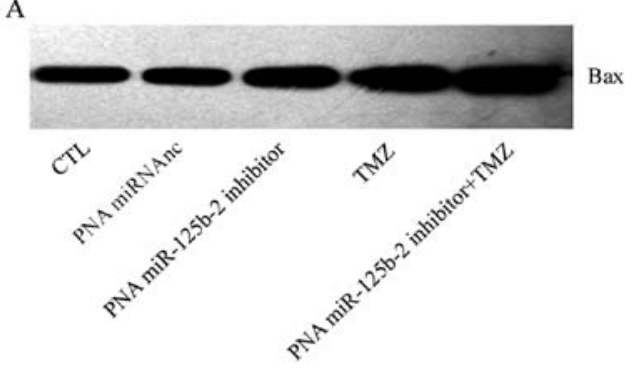

B

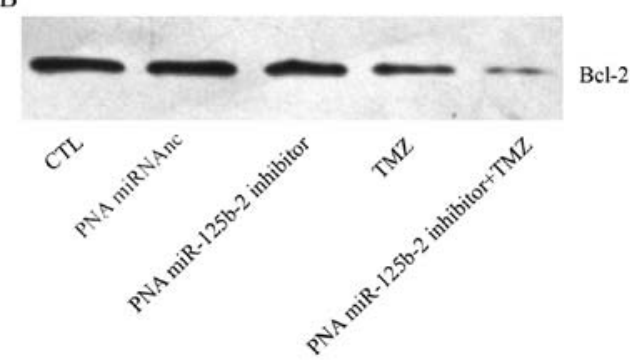

C

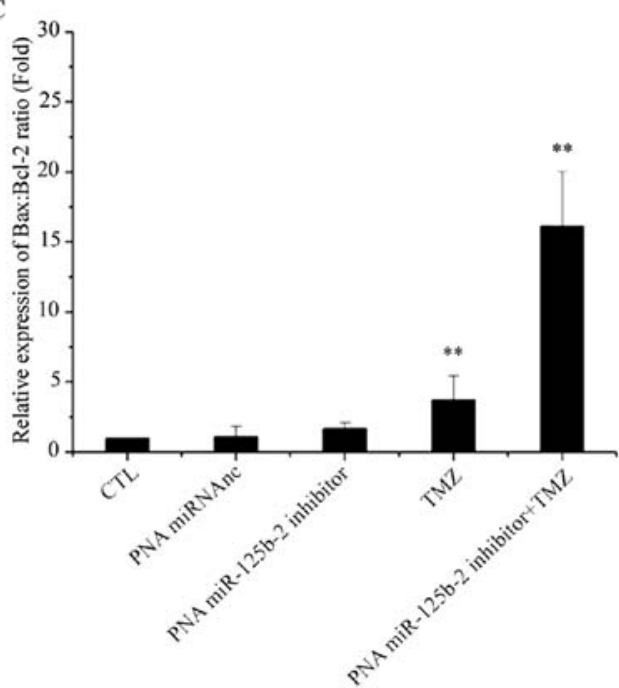

Figure 4. The combination of the PNA miR-125b-2 inhibitor and TMZ therapy increases the Bax/Bcl-2 ratio in GBMSC. GBMSC were treated with the PNA miR-125b-2 inhibitor and/or TMZ for 6 days. After each treatment, cells were harvested and measured by Western blot analysis. (A) Compared to the CTL and PNA miRNAnc groups, treatment with the PNA miR-125b-2 inhibitor and TMZ increases the expression of the proapoptotic protein Bax in GBMSC. (B) Compared to the CTL and PNA miRNAnc groups, treatment with the PNA miR-125b-2 inhibitor and TMZ decreases the expression of the antiapoptotic protein Bcl-2 in GBMSC. (C) Bar graphs represent the relative expression of the Bax/Bcl-2 ratio calculated from each group. Data are presented as the means of triplicate experiments. Significant differences between the TMZ+PNA miR-125b-2 inhibitor and TMZ or PNA miR-125b-2 inhibitor treated cells are indicated by ${ }^{* *} \mathrm{P}<0.01$.

To confirm that the inconsequence of the PNA miR125b-2 inhibitor on the increased TMZ sensitivity depended on alterations in the Bax:Bcl-2 ratio, the levels of Bax and Bcl-2 were measured by Western blot experiments in all treatment groups. In the current study, we observed that there was no significant difference $(\mathrm{P}>0.05)$ in Bax and Bcl-2 expression in the PNA miR-125b-2 inhibitor group compared to the control groups. Compared to control cells, a slight increase in Bax expression and a decrease in Bcl-2 expression were observed in cells exposed to TMZ $(\mathrm{P}<0.05)$ (Fig. 4A and $\mathrm{B})$. However, a significant increase in the Bax:Bcl-2 ratio could be observed after combine treatment with $\mathrm{TMZ}$ and the PNA miR-125b-2 inhibitor in GBMSC, compared to treatment of the cells with TMZ alone $(\mathrm{P}<0.01)$ (Fig. 4C). Taken together, these results show that the sensitizing activity of GBMSC to $\mathrm{TMZ}$ is critically determined by the cellular Bax:Bcl-2 ratio, and the intrinsic pathway of apoptosis is involved in the altered miR-125b-2 levels.

Combination of the PNA miR-125b-2 inhibitor and TMZ therapy induces cytochrome c release, induction of Apaf-1, and activation of caspase-3 and PARP cleavage in GBMSC. In biological systems, apoptosis may involve the disruption of mitochondrial function through the abnormal expression of Bcl-2 and/or Bax, which induces the release of cytochrome c from mitochondria into the cytosol. Cytosolic cytochrome c can interact with Apaf-1 and lead to the activation of caspases in the apoptosome and finally lead to the activation of caspase-3, subsequently leads to apoptosis (30). For these reasons, we determined whether the induction of apoptosis in GBMSC by the TMZ+PNA miR-125b-2 inhibitor is associated with the disruption of mitochondrial function and the activation of caspases. By Western blot analysis, we found that treatment with the PNA miR-125b-2 inhibitor did not result in a significant increase in cytochrome c and Apaf-1, whereas treatment with $600 \mu \mathrm{M}$ TMZ resulted in significant cytochrome $\mathrm{c}$ release from mitochondria and the induction of Apaf-1 $(\mathrm{P}<0.01)$. The cytochrome c release and induction of Apaf-1 were further increased when cells were incubated with the combination of the PNA miR-125b-2 inhibitor and TMZ $(\mathrm{P}<0.01)$ (Fig. 5A and B).

The release of cytochrome $\mathrm{c}$ from mitochondria, which is regulated by Bcl-2 family members and is considered to take place on the outer membrane of mitochondria, results in activation of effector caspases, which induce apoptosis. Among the effector caspases, caspase-3 is most frequently involved in neuronal apoptosis. Activated caspase- 3 is crucial for the induction of apoptosis (31). Our previous study showed that TMZ could increase the caspase- 3 activation in glioblastoma cells (15). To determine whether caspase-3 and its downstream PARP are further activated after the afore-mentioned treatments, caspase- 3 activity was measured by the caspase- 3 activity kit, while the level of PARP protein was determined by Western blot analysis. In this study, caspase-3 activity was slightly elevated after treatment with the PNA miR-125b-2 inhibitor in GBMSC; however, statistical differences in caspase-3 activity were found between the PNA miR-125b-2 inhibitor group and the control group or the negative control group $(\mathrm{P}<0.05)$. Compared to control cells, the treatment of cells with TMZ alone also caused a significant increase in caspase- 3 activation $(\mathrm{P}<0.01)$. However, such effects of caspase- 3 activity were further amplified in cells co-treated with TMZ+PNA miR-125b-2 inhibitor $(\mathrm{P}<0.01)$ (Fig. 5C). At the same time, the level of PARP cleavage protein was correspondingly upregulated in $85 \mathrm{kDa}$ under identical conditions (Fig. 5D). These results suggest that the downregulation of miR-125b-2 could significantly help TMZ activate the mitochondrial pathway of apoptosis in GBMSC.

Inhibition of caspases prevents TMZ-induced apoptosis after PNA miR-125b-2 inhibitor pre-treatment in GBMSC. Because 
A
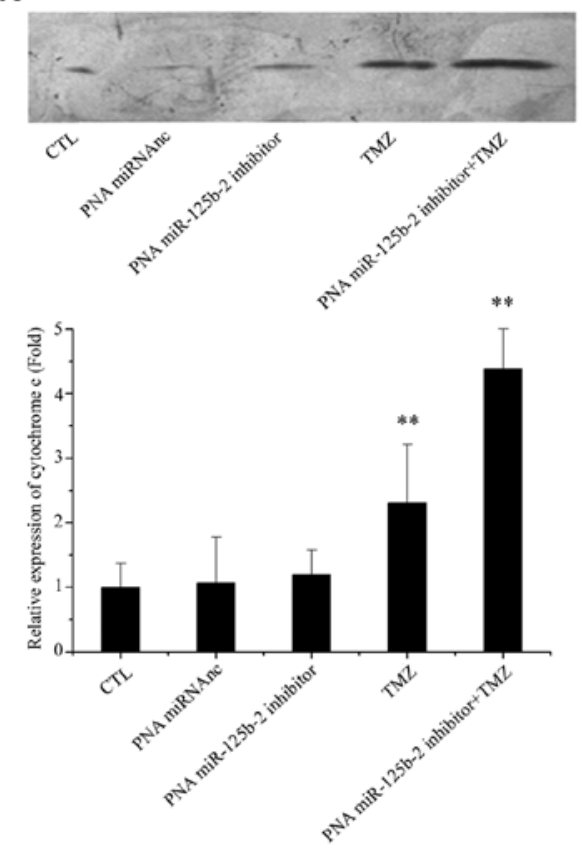

C

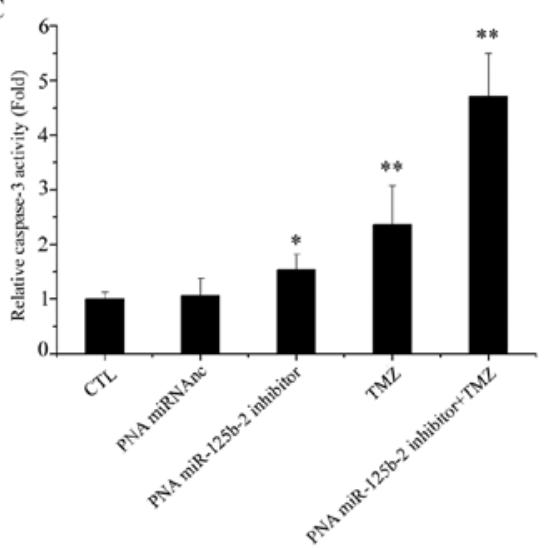

B

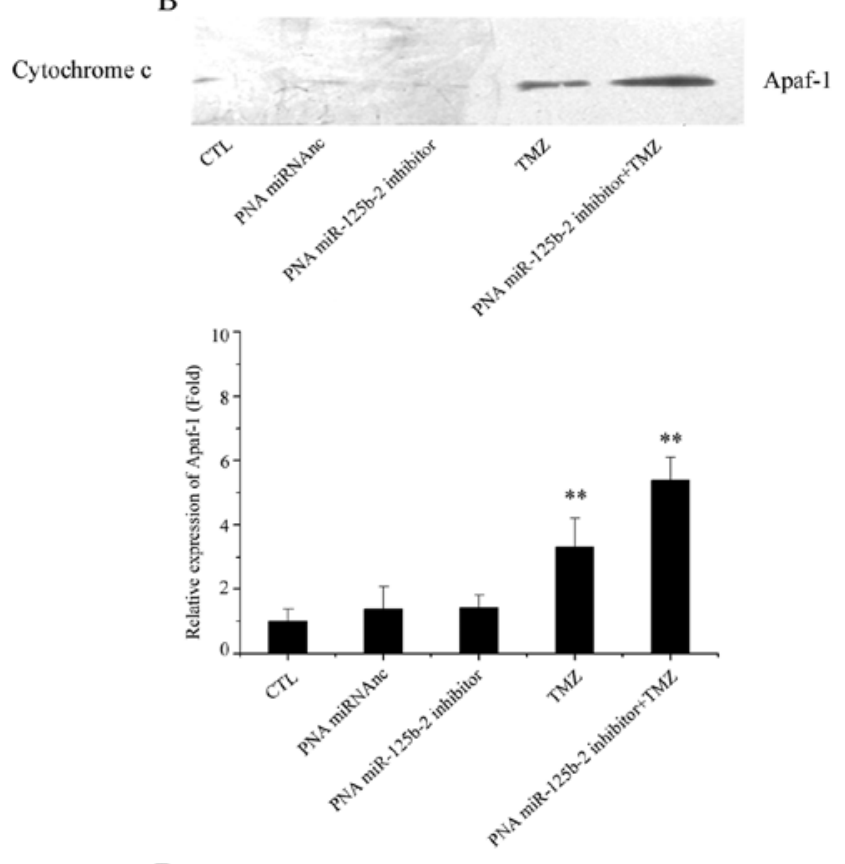

D
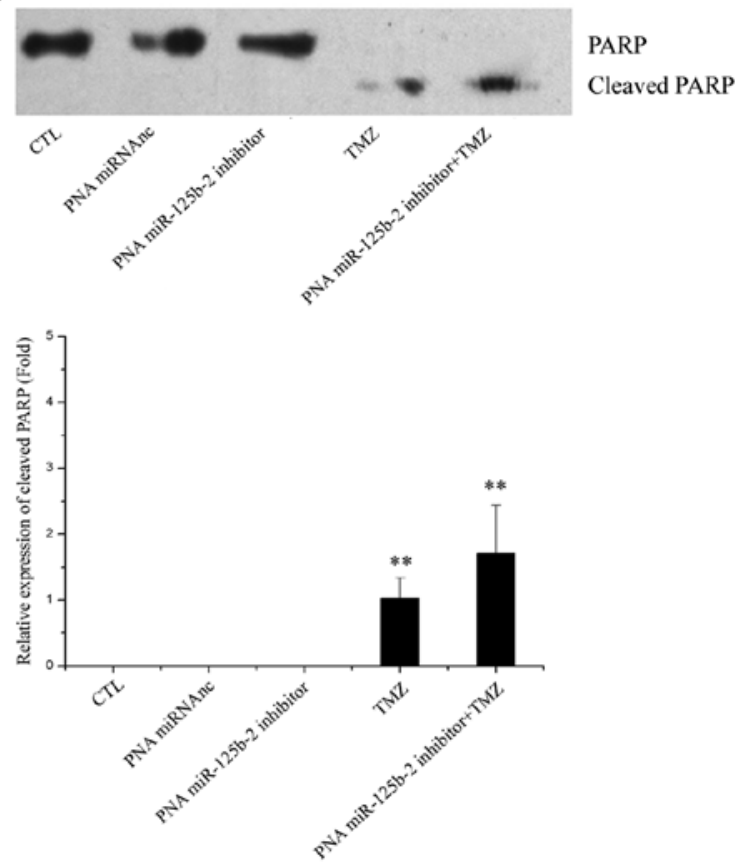

Figure 5. The combination of the PNA miR-125b-2 inhibitor and TMZ therapy induces cytochrome c release, induction of Apaf-1, and activation of caspase-3 and PARP cleavage in GBMSC. GBMSC were treated with the PNA miR-125b-2 inhibitor and/or TMZ for 6 days. After all treatments, cells were harvested and measured by Western blot analysis, and caspase-3 activity was measured by the Caspase-3 activity kit. (A) Compared with the CTL and PNA miRNAnc groups, treatment with the PNA miR-125b-2 inhibitor and TMZ increases the expression of cytochrome $c$ in GBMSC. Bar graphs represent the relative expression of cytochrome c calculated from each group. (B) Compared with the CTL and PNA miRNAnc groups, treatment with the PNA miR-125b-2 inhibitor and TMZ increases the expression of apoptotic protease-activating factor-1 (Apaf-1) in GBMSC. Bar graphs represent the relative expression of Apaf-1 calculated from each group. (C) Compared with the CTL and PNA miRNAnc groups, treatment with the PNA miR-125b-2 inhibitor and TMZ showed a significant increase in the caspase-3 activity. Bar graphs represent the relative expression of caspase-3 activity calculated from each group. (D) Compared to the CTL and PNA miRNAnc groups, treatment with the PNA miR-125b-2 inhibitor and TMZ increases the expression of cleaved PARP. Data are presented as the means of triplicate experiments. Significant differences between the TMZ+PNA miR-125b-2 inhibitor and TMZ or PNA miR-125b-2 inhibitor treated cells are indicated by ${ }^{* * *} \mathrm{P}<0.01$.

we found that the PNA miR-125b-2 inhibitor treatment further increased the activation of caspase-3 beyond what was induced by TMZ treatment alone and because this might be involved in TMZ-induced apoptosis in GBMSC, we became interested in examining whether caspase inhibi- tion could prevent TMZ+PNA miR-125b-2 inhibitor-induced apoptosis. The specific inhibitor for caspase-3, Z-VAD-FMK, was used to inhibit caspase activation. As shown in Fig. 6, the preincubation of cells with $100 \mu \mathrm{mol} / 1$ of Z-VAD-FMK for 30 min significantly inhibited TMZ+PNA miR-125b-2 
A

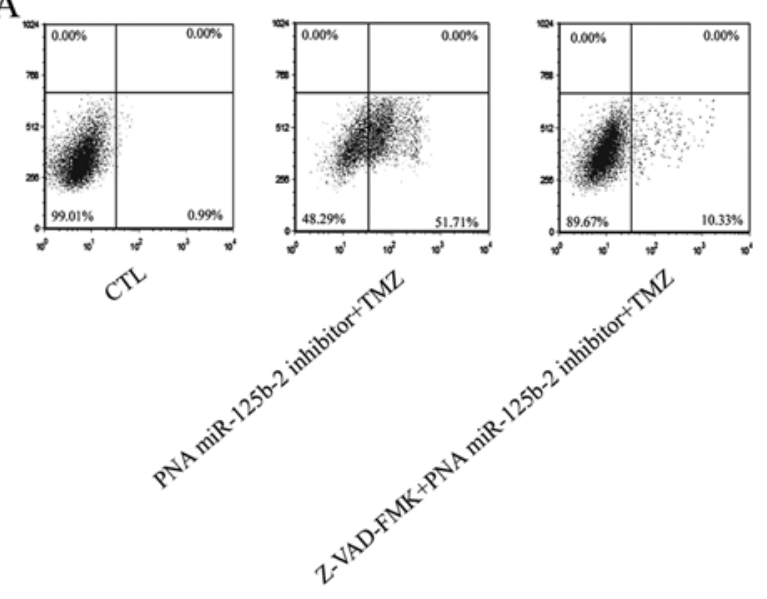

B

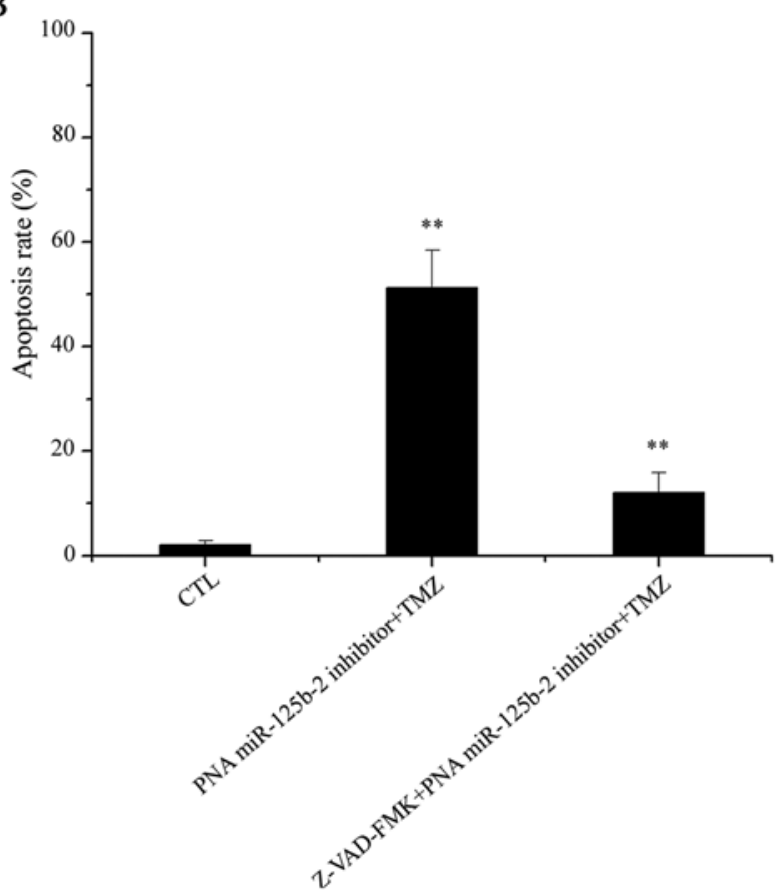

Figure 6. The combination of the PNA miR-125b-2 inhibitor and TMZ therapy-induced apoptosis is blocked by the caspase inhibitor Z-VAD-FMK in GBMSC. (A) Cells were incubated with a $100 \mu \mathrm{mol} / 1$ concentration of the general caspase inhibitor Z-VADFMK for $30 \mathrm{~min}$, followed by treatment with the PNA miR-125b-2 inhibitor and TMZ for 6 days. Cells were harvested and double stained for Annexin $\mathrm{V}$ and propidium iodide and analyzed by flow cytometry. (B) Bar graphs represent the percentage of apoptotic cells calculated from each group. Data are presented as the means of triplicate experiments. Significant differences between the TMZ+PNA miR-125b-2 inhibitor+Z-VAD-FMK and TMZ+PNA miR-125b-2 inhibitor treated cells are indicated by ${ }^{* *} \mathrm{P}<0.01$.

inhibitor-induced apoptosis $(>70 \%, \mathrm{P}<0.01)$. This suggests that TMZ+PNA miR-125b-2 inhibitor-induced apoptosis requires activation of caspases, including caspase-3.

\section{Discussion}

Temozolomide (TMZ) is a DNA-methylating agent that has recently been introduced into phase 2 and 3 trials for the treatment of gliomas (32). Previous studies have shown that TMZ can effectively inhibit glioma cell growth and induce apoptosis (33). However, the effect of TMZ in glioma cells was not ideal. A number of studies have shown that TMZ is an inducer for autophagy rather than for apoptosis in most glioma cell lines (23). Research by Fu et al showed that glioblastoma stem cells are resistant to temozolomide-induced autophagy (34).

Fortunately, the necessity of microRNA (miRNA) pathways is one of the potential key mechanisms for proper control of germline GSC division. Previous studies showed that miR-125b was necessary for stem cell fission (6). MiR-125b has also been found to affect the proliferation and apoptosis of human glioma cells. Down-regulation of miR-125b decreased human glioma cell proliferation and enhanced the sensitivity of human glioma cells to ATRA-induced apoptosis (25). In this study, we found that miR-125b-2 is strongly over-expressed in CD133-positive glioblastoma cells (GBMSC), especially in the postoperative recurrence of glioblastoma multiforme tissues after TMZ treatment. Thus, we speculate that miR-125b-2 might become a target for the regulation of the chemotherapeutic effect in cancer therapy. So far, the effect and mechanism of miR-125b-2 with respect to TMZ chemotherapeutic effect regulation has not been studied in human GBMSC. Here, we provide data indicating the importance of miR-125b-2 dysregulation in human GSCs and report for the first time that down-regulation of miR-125b-2 is a potential treatment for TMZ resistance in GBMSC.

At present, cancer drug resistance is considered a multifactorial phenomenon involving several major mechanisms, such as a decreased uptake of water-soluble drugs, an increased repair of DNA damage, reduced apoptosis, altered metabolism of drugs, and an increased energy-dependent efflux of chemotherapeutic drugs that diminish the ability of cytotoxic agents to kill cancer cells (35). miRNA expression that affected multiple genes simultaneously provided support for this hypothesis (36). Recent findings in our lab have confirmed a critical role for miR- $125 \mathrm{~b}$ as a powerful cellular prolification indicator of human glioma U251 stem cells, resulting in the development of novel approaches to glioma stem cell management (20). Despite the well-established role of miR-125b-2 in gliomas and the dedication of research on the elucidation of the molecular mechanisms involved in the development of gliomas cells that are resistant to chemotherapy, the role of miR-125b-2 in human GBMSC and drug resistance remains largely unexplored (7). In view of the overexpression of miR-125b-2 in human GBMSC, we explored the function of miRNA inhibition. The inhibition of miRNAs using antisense oligonucleotides (ASOs) is a unique and effective technique for the characterization and subsequent therapeutic targeting of miRNA function. Recent advances in ASO chemistry have been used to increase both the resistance to nucleases and the target affinity and specificity of these ASOs. Peptide nucleic acids (PNAs) are synthetic nucleic acid analogues in which the sugar-phosphate backbone of the nucleic acid has been replaced by an uncharged N-(2-aminoethyl)-glycine scaffold. Compared to DNA-RNA duplexes, PNA-RNA duplexes exhibit an increased thermal stability. PNA-based ASOs could be used to inhibit miRNA regulation of gene expression and function in mammalian cells with more potency than other miRNA inhibitors (22). In this study, we found that the PNA miR-125b-2 inhibitor successfully inhibited the expression of miR-125b-2 in human GBMSC. We also found a relationship between miR-125b-2 and TMZ-induced apoptosis in human GBMSC. 
Our data show that TMZ, in fact, could not induce GBMSC apoptosis; however, pretreating human GBMSC with the PNA miR-125b-2 inhibitor increased the chemotherapeutic action of TMZ and promoted GBMSC apoptosis. These results strongly suggest that the downregulation of miR-125b-2 treatment could interfere with the chemotherapeutic efficacy of TMZ on human GBMSC.

Several in vitro studies have documented a role for miR-125b or TMZ in human glioma cells. However, the mechanisms of miR-125b-2-mediated, TMZ-induced cell death are not yet fully understood in human GBMSC. Apoptosis is regulated by several protein families, including the upstream Bcl-2 family and the downstream caspase family (31). The Bcl-2 family consists of both proapoptotic and antiapoptotic members that elicit opposing effects on mitochondria. Bax can promote the release of cytochrome $\mathrm{c}$ from mitochondria into the cytosol, which in turn activates caspase-3, one of the key executioners of apoptosis and PARP (37). The antiapoptotic proteins, such as Bcl-2, preserve the integrity of the mitochondria, which blocks the release of cytochrome $\mathrm{c}$ that would otherwise activate the effectors of apoptosis (38). Bcl-2 serves as a powerful antidote to cell death and may counteract the effect of both caspasedependent and -independent modes of cell death (39). In addition to being described as an inhibitor of the apoptotic pathway, $\mathrm{Bcl}-2$ has been implicated as having strong antioxidant properties and thus may provide a common survival function in apoptotic and oxidative stress patterns of cellular injury (40). Importantly, the ratio of pro- and antiapoptotic protein expression, such as Bax/ $\mathrm{Bcl}-2$, is critical for the induction of apoptosis, and the ratio of $\mathrm{Bax} / \mathrm{Bcl}-2$ decides a cell's susceptibility to undergo apoptosis. A change in the ratio of $\mathrm{Bax} / \mathrm{Bcl}-2$ stimulates the release of cytochrome $\mathrm{c}$ from mitochondria into cytosol. Cytochrome $\mathrm{c}$ can interact with cytosolic protein Apaf-1 and lead to the activation of caspase-3 activity with degradation of PARP (30). Previous studies have shown that treatment with TMZ changes the expression of pro-apoptotic Bax and anti-apoptotic Bcl-2 involved in the mitochondrial pathway of apoptosis (41). Si et al and Li et al recently showed that knockdown of miR-21 inhibited tumor cell growth in vitro and in vivo by effecting an increase in apoptosis associated with the downregulation of Bcl-2 expression and upregulation of Bax expression (42). Thus, we examined the levels of expression of Bax and Bcl-2 proteins in human GBMSC following treatment with TMZ and the PNA miR-125b-2 inhibitor. In this study, we found that the pretreatment of cells with the PNA miR-125b-2 inhibitor prior to TMZ treatment appeared to result in an increase in the $\mathrm{Bax} / \mathrm{Bcl}-2$ ratio, the release of cytochrome $\mathrm{c}$, the expression of Apaf-1, activity of caspase-3, and the expression of cleaved PARP protein compared with treatment with TMZ alone; this indicates an efficient increase in the effect of the PNA miR-125b-2 inhibitor on TMZ-mediated regulation in Bax:Bcl-2 ratios.

Previous research has demonstrated that Bcl-2 acts to prevent the release of cytochrome $\mathrm{c}$ and the activation of caspase, while Bax has the opposite function, promoting the release of cytochrome $\mathrm{c}$ from mitochondria into the cytosol and activates caspase 3 (43). The microinjection of cytochrome $\mathrm{c}$ induces apoptosis, as has been found in human kidney 293 cells and NRK cells (44). To further confirm the role of caspase activation in TMZ+PNA miR-125b-2 inhibitor-induced apoptosis, we observed that treatment with the caspase inhibitor, Z-VAD-FMK, prevented TMZ+PNA miR-125b-2 inhibitor-induced apoptosis in GBMSC. In this study, we found that the combined treatment of GBMSC with TMZ and the PNA miR-125b-2 inhibitor significantly induced apoptosis, accompanied by an increased caspase- 3 activation, whereas significantly less apoptosis was observed in the cells treated with the caspase inhibitor, Z-VAD-FMK; this indicates that caspase was responsible for the induction of apoptosis. These results provide evidence for the importance of the caspase pathway in apoptosis induced by TMZ in combination with the PNA miR-125b-2 inhibitor.

In conclusion, the results of the present study indicate that apoptosis induced by TMZ in combination with the PNA miR-125b-2 inhibitor in GBMSC cells is primarily mediated through a mitochondria-dependent pathway and involves proteins of the Bcl-2 family, cytochrome c, Apaf-1, and the activation of both caspase- 3 and PARP. The PNA miR$125 \mathrm{~b}-2$ inhibitor could, at least in part, be allowing TMZ to induce the activation of mitochondria-related apoptosis. These results also suggest that miR-125b-2 downreguation has the potential to disrupt the resistance of glioblastoma stem cells to TMZ.

\section{Acknowledgments}

This work was supported by China National Natural Scientific Fund (81072078, 81000963, 30200335 and 30872657), Jiangsu Province's Medical Major Talent Program (RC2007061), Jiangsu Province's Natural Science Foundation (BK2008475, 2009444 and 2010580), Program for Development of Innovative Research Teamin the First Affiliated Hospital of NJMU, Suzhou Social Development Foundation (SYS201063, KS1006, KS1009) and the Priority Academic Program Development of Jiangsu Higher Education Institutions.

\section{References}

1. Yung WK, Kyritsis AP, Gleason MJ and Levin VA: Treatment of recurrent malignant gliomas with high-dose 13-cis-retinoic acid. Clin Cancer Res 2: 1931-1935, 1996.

2. Agarwala SS and Kirkwood JM: Temozolomide, a novel alkylating agent with activity in the central nervous system, may improve the treatment of advanced metastatic melanoma. Oncologist 5: 144-151, 2000.

3. Athanassiou H,Synodinou M,Maragoudakis E, et al: Randomized phase II study of temozolomide and radiotherapy compared with radiotherapy alone in newly diagnosed glioblastoma multiforme. J Clin Oncol 23: 2372-2377, 2005.

4. Vescovi AL, Galli R and Reynolds BA: Brain tumour stem cells. Nat Rev Cancer 6: 425-436, 2006.

5. Singh SK, Hawkins C, Clarke ID, et al: Molecular hydrogen beyond the optical edge of an isolated spiral galaxy. Nature 432: 396-401, 2004.

6. Hatfield SD, Shcherbata HR, Fischer KA, Nakahara K, Carthew RW and Ruohola-Baker H: Stem cell division is regulated by the microRNA pathway. Nature 435: 974-978, 2005.

7. Lee YS, Kim HK, Chung S, Kim KS and Dutta A: Depletion of human micro-RNA miR-125b reveals that it is critical for the proliferation of differentiated cells but not for the down-regulation of putative targets during differentiation. J Biol Chem 280: 16635-16641, 2005.

8. Winkler JA, Hendricks WP, Johnson D, Xia J and Scheck AC: Global microRNA expression analysis in human malignant glioma cells reveals novel miRNA-mediated therapy-resistance mechanisms. AACR Meeting Abst, 1398, 2005.

9. Oh SY, Ju Y, Kim S and Park H: PNA-based antisense oligonucleotides for microRNAs inhibition in the absence of a transfection reagent. Oligonucleotides 20: 225-230, 2010. 
10. Manero F, Gautier F, Gallenne T, Cauquil N, Grée D and Cartron P: The small organic compound ha14-1 prevents bcl-2 interaction with bax to sensitize malignant glioma cells to induction of cell death. Cancer Res 66: 2757-2764, 2006.

11. Wick W, Grimmel C, Wild-Bode C, Platten M, Arpin M and Weller M: Ezrin-dependent promotion of glioma cell clonogenicity, motility, and invasion mediated by bcl- 2 and transforming growth factor-2. J Neurosci 21: 3360-3368, 2001.

12. Cartron P, Oliver L, Martin S, et al: The expression of a new variant of the pro-apoptotic molecule Bax, Bax, is correlated with an increased survival of glioblastoma multiforme patients. Hum Mol Genet 11: 675-687, 2002.

13. Shinoura N, Yoshida Y, Nishimura M, et al: Expression level of bcl-2 determines anti- or proapoptotic function. Cancer Res 59: 4119-4128, 1999.

14. Salakou S, Kardamakis D, Tsamandas AC, et al: Increased Bax/ Bcl-2 ratio up-regulates caspase-3 and increases apoptosis in the thymus of patients with myasthenia gravis. In Vivo 21: 123-132, 2007.

15. Shi L, Chen J, Yang J, et al: MiR-21 protected human glioblastoma U87MG cells from chemotherapeutic drug temozolomide induced apoptosis by decreasing $\mathrm{Bax} / \mathrm{Bcl}-2$ ratio and caspase- 3 activity. Brain Res 1352: 255-264, 2010.

16. Darling JL: The in vitro biology of human brain tumors. In: Neurooncology: Primary Malignant Brain Tumors. Thomas DGT (ed.) Johns Hopkins University Press, Baltimore, MD, pp1-25, 1990.

17. Chen C, Ridzon DA, Broomer AJ, et al: Real-time quantification of microRNAs by stem-loop RT-PCR. Nucleic Acids Res 33: e179, 2005.

18. Livak KJ and Schmittgen TD: Analysis of relative gene expression data using real-time quantitative PCR and the 2 [-Delta Delta C(T)] method. Methods 25: 402-408, 2001.

19. Ito H, Aoki H, Kühnel F, et al: Autophagic cell death of malignant glioma cells induced by a conditionally replicating adenovirus. J Natl Cancer Inst 98: 625-636, 2006.

20. Shi L, Zhang J, Pan T, Zhou J, et al: MiR-125b is critical for the suppression of human U251 glioma stem cell proliferation. Brain Res 1312: 120-126, 2010

21. Ostermann S, Csajka C, Buclin T, et al: Plasma and cerebrospinal fluid population pharmacokinetics of temozolomide in malignant glioma patients. Clin Cancer Res 10: 3728-3736, 2004.

22. Oh SY, Ju Y and Park H: A highly effective and long-lasting inhibition of miRNAs with PNA-based antisense oligonucleotides. Mol Cells 28: 341-345, 2009.

23. Fu J, Liu ZG, Liu XM, et al: Glioblastoma stem cells resistant to temozolomide-induced autophagy. Chin Med J 122: 1255-1259, 2009.

24. Narayan P, Mentzer RM Jr and Lasley RD: Annexin V staining during reperfusion detects cardiomyocytes with unique properties. Am J Physiol Heart Circ Physiol 281: H1931-H1937, 2001

25. Xia HF, He TZ, Liu CM, et al: MiR-125b expression affects the proliferation and apoptosis of human glioma cells by targeting Bmf. Cell Physiol Biochem 23: 347-358, 2009.

26. Das A, Banik NL, Patel SJ and Ray SK: Dexamethasone protected human glioblastoma U87MG cells from temozolomide induced apoptosis by maintaining Bax:Bcl-2 ratio and preventing proteolytic activities. Mol Cancer 3: 36-45, 2009.

27. Bojes HK, Suresh PK, Mills EM, Spitz DR, Sim JE and Kehrer JP: Bcl-2 and Bcl-xL in peroxide-resistant A549 and U87MG cells. Toxol Sci 42: 109-116, 1998.
28. Terrano DT, Upreti $M$ and Chambers TC: Cyclin-dependent kinase 1-mediated $\mathrm{Bcl}-\mathrm{xL} / \mathrm{Bcl}-2$ phosphorylation acts as a functional link coupling mitotic arrest and apoptosis. Mol Cell Biol 30: 640-656, 2010

29. Weller M, Schmidt C, Roth W and Dichgans J: Chemotherapy of human malignant glioma: prevention of efficacy by dexamethasone? Neurology 48: 1704-1709, 1997.

30. Katiyar SK, Roy AM and Baliga MS: Silymarin induces apoptosis primarily through a p53-dependent pathway involving Bcl-2/Bax, cytochrome $\mathrm{c}$ release, and caspase activation. Mol Cancer Ther 4: 207-216, 2005.

31. Jarskog LF, Selinger ES, Lieberman JA and Gilmore JH: Apoptotic proteins in the temporal cortex in schizophrenia: high bax/bcl-2 ratio without caspase-3 activation. Am J Psychiatry 161: 109-115, 2004.

32. Hirose Y, Berger MS and Pieper RO: p53 effects both the duration of $\mathrm{G} 2 / \mathrm{M}$ arrest and the fate of Temozolomide-treated human glioblastoma cells. Cancer Res 61: 1957-1963, 2001.

33. Kim JT, Kim JS, Ko KW, et al: Metronomic treatment of temozolomide inhibits tumor cell growth through reduction of angiogenesis and augmentation of apoptosis in orthotopic models of gliomas. Oncol Rep 16: 33-39, 2006.

34. Fu J, Shao CJ, Chen FR, Ng HK and Chen ZP: Autophagy induced by valproic acid is associated with oxidative stress in glioma cell lines. Neurooncology 12: 328-340, 2010.

35. Prokopenko O and Mirochnitchenko O: Ischemia-reperfusioninducible protein modulates cell sensitivity to anticancer drugs by regulating activity of efflux transporter. Am J Physiol Cell Physiol 296: C1086-C1097, 2009.

36. Mendes ND, Freitas AT and Sagot MF: Current tools for the identification of miRNA genes and their targets. Nucleic Acids Res 37: 2419-2433, 2009.

37. Reed JC: Regulation of apoptosis by Bcl-2 family proteins and its role in cancer and chemoresistance. Curr Opin Oncol 7: 541-546, 1995.

38. Ryan KM, Phillips AC and Vousden KH: Regulation and function of the p53 tumor suppressor protein. Curr Opin Cell Biol 13: 332-337, 2001.

39. Kroemer G: The proto-oncogene Bcl-2 and its role in regulating apoptosis. Nat Med 3: 614-620, 1997.

40. Lee L, Irani K and Finkel T: Bcl-2 regulates non-apoptotic signal transduction: inhibition of c-Jun N-terminal kinase (JNK) activation by IL-1 beta and hydrogen peroxide. Mol Genet Metab 64: 19-24, 1998.

41. Ma J, Murphy M, O'Dwyer PJ, Berman E, Reed K and Gallo JM: Biochemical changes associated with a multidrug-resistant phenotype of a human glioma cell line with temozolomideacquired resistance. Biochem Pharmacol 63: 1219-1228, 2002.

42. Li F, Srinivasan A, Wang Y, Armstrong RC, Tomaselli KJ and Fritz LC: Cell-specific induction of apoptosis by microinjection of cytochrome c. Bcl-xL has activity independent of cytochrome c release. J Biol Chem 272: 30299-30305, 1997.

43. Kluck RM, Bossy-Wetzel E, Green DR and Newmeyer DD: The release of cytochrome $\mathrm{c}$ from mitochondria: a primary site for Bcl-2 regulation of apoptosis. Science 275: 1132-1136, 1997.

44. Zhivotovsky B, Orrenius S, Brustugun OT and Doskeland SO: Injected cytochrome c induces apoptosis. Nature 391: 449-450, 1998. 